The original publication is available at www.actahort.org

http://www.actahort.org/members/showpdf?session=22760

\title{
The Adoption of Quality Management Systems in the Fresh Produce Industry in Western Australia
}

G. Kuepper and P.J. Batt

Curtin University

Perth

Western Australia

\begin{abstract}
In an examination of 37 fresh fruit and vegetable processing businesses in Perth, Western Australia, comparisons are drawn between those firms which have adopted a third party certified quality assurance (QA) system and those which have chosen not to adopt. Seven firms chose not to implement a QA system, citing high cost, lack of time, company structure and lack of statutory requirement for QA. Of those companies implementing QA, the deciding factor was a desire to meet the customers' requirements. Firms held the belief that QA would enable them to better meet customer needs, provide greater customer assurance, improve communication, gain new customers, improve supplier relationships and ultimately to increase market share. The largest obstacle for the adoption of QA initially was the reluctance of employees to engage in the process. Subsequent obstacles were increased paperwork, high cost, lack of time, lack of suitably qualified staff and the need for more knowledgeable staff. Conversely, firms choosing not to use QA perceived themselves to be too small and to be constrained by the lack of capital and lack of incentives for adoption, such as customer requirements for QA.
\end{abstract}

\section{INTRODUCTION}

The food industry is a large and vital part of the Australian economy. In 20062007, total consumer expenditure on food and liquor was nearly AUD 106.6 billion, around $46 \%$ of total retail turnover (Department of Foreign Affairs and Trade, 2008). Food exports reached a peak of AUD 30.8 billion in 2001-02, but have been declining ever since. Reasons for the decline include the recent drought, but of far greater significance are the changes in import demand from overseas customers (ABARE, 2007). While most Australian food businesses recognise and acknowledge the importance of operating under an approved quality assurance (QA) system to deliver safe food, over time, there has been a steady decline in the relative importance Australian food producers give to QA programs. As a result, the Australian food industry is beginning to loose its competitive advantage (Baines et al., 2006).

Food processing is Australia's largest manufacturing industry generating total sales of around AUD 71.4 billion in 2005-06 (Department of Foreign Affairs and Trade, 2008). More than $80 \%$ of food and beverage production is located in the three eastern states of Victoria, New South Wales and Queensland. 
In the State of Western Australia, the food and beverage industry generated sales worth AUD 5.5 billion in 2006-2007 (WAAFFI, 2007). The food industry accounted for $14 \%$ of WA manufacturing industry and $7.5 \%$ of the Australian food processing industry. However, in WA, less than $10 \%$ of the 2,000 plus registered food companies currently have an accredited food safety program (Batt et al., 2006).

In order to identify the food safety and QA programs that were currently being used by food processors and manufacturers in WA and to evaluate the benefits, barriers and costs associated with the decision to adopt one or more QA program(s), a project commissioned by the WA Department of Agriculture and Food was conducted. This paper reports only upon those firms engaged in the fresh produce industry.

\section{METHODOLOGY}

This study was conducted in two phases. The first phase, which was conducted from July 2006 to September 2007, involved an exploratory investigation of the WA food processing and manufacturing sector with a view to identifying the characteristics of the industry and how these impacted upon the likelihood of adopting one or more QA systems. A comprehensive questionnaire was developed and pre-tested among a sample of QA managers, business owners and QA experts in personal interviews.

In the second phase, from March 2008 to September 2008, a postal survey to 798 food and beverage businesses including face-to-face interviews with respondents was undertaken. Respondents occupied a number of positions in the food processing industry in a range of micro, small and medium-sized enterprises (SMEs).

Despite the considerable size of the survey instrument, respondents only had to answer those questions which reflected the current stage to which QA had been implemented, maintained or even abandoned within the business. The questionnaire was subdivided in two sections and then: (1) PART A: if the business had no intention of implementing a QA program; (2) PART B: if the business had started to implement a QA program(s); (3) PART C: if the business had successfully implemented a QA program(s); and (4) PART D: if the business no longer had a QA program.

The completed questionnaires (218) were returned to Curtin University either electronically, via the fax or via the mail. Responses were encoded and entered into the Statistical Package for Social Sciences (SPSS, version 17) for analysis. Differences between those firms that had chosen to adopt QA and those who had chosen not to adopt QA were compared using the independent samples t-test.

\section{RESULTS AND DISCUSSION}

A total of 37 responses were received from firms engaged in the wholesale marketing, export and value-added processing of fresh fruit and vegetable products in WA. Growers were purposefully excluded, except where it was known that they were engaged in some value-adding activity as an integral part of their business.

Within the sample, there was considerable variance. While three firms had been trading for less than 5 years, four firms had been trading for more than 50 years. For seven firms, the turnover ranged from less than AUD 250,000 per annum to more than AUD 5 million per annum for 17 firms. Three firms employed more than 50 people. For most firms, the domestic market provided the majority of sales $(84 \%)$, with interstate sales contributing $13 \%$ and exports just $3 \%$ of total sales.

Among the respondents, 7 firms had no intention of implementing a QA system, 2 were in the process of implementing a QA system and 28 had one of more QA systems in 
operation. The most popular QA systems in operation were: HACCP (68\%), SQF 2000 (57\%) and the Woolworth's Management Standard (WQA)(36\%). Both SQF 2000 and the WQA have their origins in the horticulture sector, but both have since been extended to include other food sectors (Peters, 1998). Both of these third party certified standards have adopted the HACCP principles to manage both quality and food safety.

Six firms $(21 \%)$ operated under a generic Good Manufacturing Practice (GMP) program and 5 firms (18\%) operated under FreshCare. Only 3 firms operated under GlobalGAP, 3 firms under the Spotless QA program and 2 under an ISO 9000 series program. While there is no immediate need to certify fresh fruit and vegetable processing under halal, for the one firm that had pursued halal certification, it did provide customers with an assurance that the plant and equipment utilised was not being used to process any non-halal products.

The financial turnover of the business was found to have a positive and significant impact on the likelihood of adopting a QA program. For those firms where their annual turnover was less than AUD 250,000 per annum, 71\% did not intend to implement a QA system. Conversely, all of the firms earning more than AUD 5 million per annum had at least one QA system in operation. No relationship was found between the intended market (domestic or export) and the likelihood of adopting a QA system, suggesting that the main drivers for the adoption of a QA system were either internal or firms trading in the domestic market were compelled by their customers to have a preferred QA system.

\section{The motivation to implement a QA system}

For the 28 firms that had implemented a QA system, the main reason for doing so was to comply with customer requirements (Table 1). As several of the fresh fruit and vegetable processing firms were supplying semi-prepared products to supermarkets, fast food chains and food caterers, not unexpectedly, their customers required them to operate under either a proprietary QA program, such as Spotless or the WQA, or an independent third party certified system such as SQF 2000 or ISO 9000.

Nevertheless, it was apparent that a number of other factors had also influenced the firm's decision to implement a QA system. Some $32 \%$ of firms had adopted a QA system as a means of improving efficiency, with an additional $21 \%$ seeking to obtain some competitive advantage. Market leadership (14\%), improved market access (7\%) and an improved company image (7\%) were some of the other internal drivers. For some $27 \%$ of firms, QA had been adopted to signal to customers the firm's commitment to food quality and safety, with a further $21 \%$ suggesting that it enhanced customer's confidence. With the rise of private standards, driven primarily by the supermarkets and large multinational fast food companies (Batt, 2001), a QA system was perceived by some $14 \%$ of firms to minimise the potential exposure to litigation and the associated costs of recalling defective product.

Stamou (2003), Mutlu et al. (2003) and Henson (2008) argue that the benefits derived from the implementation of a QA program can be grouped into two categories: internal benefits and external benefits. Firm driven (internal) benefits include: (1) organizational benefits; (2) financial benefits; (3) people benefits; and (4) general benefits. Customer and regulatory driven (external) benefits include: (1) commercial benefits; (2) communication benefits; (3) quality and safety benefits; and (4) general benefits. Using these categories, it soon became apparent that the external benefits were more influential in facilitating the adoption of a QA system than the internal benefits (Table 2). Between those firms that chose to adopt a QA system and those that chose not 
to, three external communication benefits (enhanced communication with customers, improved relationships with suppliers and the capacity to provide customer assurances) and three external commercial benefits (the ability to meet customer's requirements, to gain new customers and to improve market share) were perceived to be significantly more important by those firms that chose to implement a QA system.

\section{Barriers and constraints to the adoption of QA programs}

In implementing a QA system, firms face a multitude of problems including the lack of finance, difficulties in exploiting technology, low productivity and the burdens imposed by regulatory authorities (Kuepper and Batt, 2009). Unfavourable attitudes and perceptions of QA by owner-managers, a low level of employee awareness, minimal involvement in the process, time constraints and the lack of financial incentives present additional barriers. According to Kleinwechter and Grethe (2006), even if the ownermanager can be convinced of the need to implement and maintain one or more QA programs, the allocation of sufficient time for its development and implementation will be a constraining factor.

Whereas the drivers for the adoption of QA are primarily external, the majority of the impediments are internal. Panisello and Quantick (2001) consider the barriers to the adoption of QA under three headings: (1) the lack of quality leadership and a lack of cooperation between industry and regulatory authorities; (2) staff persisting with old work habits, attitudes and the lack of time to successfully adopt and implement a QA program; and (3) the lack of harmonization between QA systems.

Noonan and Janes (2004) describe the adoption of QA programs as complicated, whereby different constraints appear at different stages in the process of implementation. For those firms in the WA fresh fruit and vegetable industry that chose not to implement a QA system, the main constraints identified were: the high cost of QA (43\%), the company structure (29\%), the lack of time and resources (29\%) and the fact that there was no legal requirement for them to have a QA system (Table 3).

For those firms that were either in the process of implementing a QA system or had at least one QA system operating in their business, the major constraints were associated with the reluctance of employees to engage (37\%); the additional paperwork required (30\%); the high level of knowledge required (30\%); the lack of suitably qualified staff $(26 \%)$; and the high costs of auditing and certification (22\%)(Table 4).

In a similar manner to their expose on the benefits of QA, Mutlu et al. (2003), Stamou (2003) and Henson (2008) grouped the barriers and constraints to the adoption of QA under two main categories: internal barriers (resources, attitudes and perceptions, implementation, and general barriers) and external barriers (support and guidance, economics, certifiers and verifiers, and general barriers). In comparing the perceived importance of the constraints between those firms that had chosen to implement QA and those that had no intention of implementing QA, significant differences were observed between ten variables (Table 5).

For those firms that had chosen not to adopt a QA system, there was a perception that the products they were producing already met their customers' requirements. As such, there was no need for a QA system, nor were there sufficient incentives to encourage them to adopt a QA system. Furthermore, there was no statutory requirement for them to have an operational QA system. However, those firms that chose not to adopt QA also spoke of the lack of any promotion by the public sector to facilitate the adoption of QA among small food enterprises and the difficulties they experienced in obtaining any external funding to facilitate the process. 
Nevertheless, among those firms that had chosen not to adopt a QA system, a number of internal constraints were also ranked more highly including; the perception that the firm was too small; the lack of appropriately trained staff; financial constraints; and the current short-term business philosophy. This highlights the challenges in implementing QA programs within small businesses because of their small size and limited resources (Aggelogiannopoulos et al., 2007).

\section{CONCLUSIONS}

While QA may be an instrument to differentiate the product offer, for the majority of food businesses, the decision to implement a QA system is more often the result of customer pressures rather than the perceived benefits such as improved efficiency and effectiveness (Karipidis et al., 2009; Chemnitz, 2007).

Porter (1985) maintains that competitiveness is embodied in the characteristics of the firm, namely through the current efficiency and effectiveness of resource use; the willingness and the ability to relate profitability to growth through continued investment; and the ability to innovate in technology and organization to improve efficiency and effectiveness in production and marketing. While the use of QA systems in the food processing industry is often seen as an indicator of competitiveness, a distinction must be made between the more prescriptive codes of practice and those QA programs that focus on continuous improvements in productivity and product quality (Batt et al., 2006). Here it is important to recognise that while the prescriptive codes of practice may assure downstream customers that the food is safe, the implementation of such systems will have little impact on improving or enhancing competitiveness, other than to facilitate greater market access.

\section{Literature Cited}

ABARE. 2007. Australian commodities march quarter 2007, Australian food industry performance and competitiveness, Canberra, 1-10.

Aggelogiannopoulos, D., Drossinos, E.H. and Athanasopoulos, P. 2007. Implementation of a quality management system according to ISO 9000 family in a Greek small-sized winery: A case study. Food Control 18: 1077-1085.

Baines, R.N., Davies, W.P. and Batt, P.J. 2006. Benchmarking International Food Safety and Quality Systems: Towards a Framework for Fresh Produce in the Transitional Economies. Acta Horticulturae 699: 69-76.

Batt, P.J. 2001. Relational quality: further evidence of a single higher order construct in an industrial market. Interactions, Relationships and Networks: Strategic Dimensions. Proceedings 17th Annual IMP Conference. Oslo. Norwegian Institute of Management.

Batt, P.J., Noonan, J. and Kenyon, P. 2006. Global trends analysis of food safety and quality systems for the Australian food industry. Report for the Department of Agriculture, Fisheries and Forestry. Canberra. 1-135.

Chemnitz, C. 2007. The Compliance Process of Food Quality Standards on the Primary Producer Level: A Case Study of EUREPGAP Standard in the Moroccan Tomato Sector. Working Paper 81/2007. Humboldt University Berlin, Germany.

Department of Agriculture and Food -WAAFFI. 2007. Western Australia's Agri-Food, Fibre and Fisheries Industries 2007, 1-72.

Department of Foreign Affairs and Trade. 2008. Australian Government - about Australia. Fact sheet series. Food industry in Australia. 
Henson, S. 2008. Public and private incentives to adopt enhanced food safety controls: Paper presentation at IAMO Forum 2008, Agri-Food Business: Global Challenges Innovative Solutions.

Karipidis, P., Athanassiadis, K., Agglopolos, S. and Giompliakis, E. 2009. Factors affecting the adoption of quality assurance systems in small food enterprises. Food Control 20: 93-98.

Kleinwechter, U. and Grethe, H. 2006. The significance and adoption of food quality and safety standards in developing countries - a case study for the EurepGap standard in the mango export sector in Piura, Peru Paper presented at IAAEC, Gold Cost, Australia, 1-15.

Kuepper, G and Batt, P.J. 2009. Barriers to the adoption of quality assurance systems in the food and beverage sector. Stewart Postharvest Review 5(3): 1-5.

Mutlu, S., Bal, T., Say, D. and Emeksiz, F. 2003. The Adoption and Implementation of the Food Quality System (HACCP) in Mediterranean Region of Turkey. In Nikolaidis A., Baourakis, G., Isikli, E. and Yercan, M. (ed.) The market for organic products in the Mediterranean region. CIHEAM-IAMC: 201-217.

Noonan J. and Janes J. 2004. An overview of food quality and safety management. Agriculture Congress: innovation towards modernized agriculture: 422-428

Panisello, P.J. and Quantick, P.C. 2001. Technical barriers to Hazard Analysis Critical Control Point (HACCP). Food Control 12: 165-173

Peters, R.E. 1998. The broader application of HACCP concepts to food quality in Australia. Food Control 9(2-3): 83-89.

Porter, M.E. 1985. Competitive Advantage: Creating and Sustaining Superior Performance. Free Press, New York.

Stamou, T. 2003. Integrated Management Systems in Small Medium-Sized Enterprises: Theory and Practice, Master Thesis, University of East Anglia, 1-79

Table 1: Main reasons for the adoption of QA programs

\begin{tabular}{|l|c|c|}
\hline & $\mathrm{N}$ & $\%$ \\
\hline Satisfy customer requirements & 28 & 100.0 \\
\hline Improve business efficiency & 9 & 32.1 \\
\hline Commitment to food quality and safety & 8 & 26.6 \\
\hline Consumer confidence & 6 & 21.4 \\
\hline Competitive advantage & 6 & 21.4 \\
\hline Market leadership & 4 & 14.3 \\
\hline Reduce legal liability/insurance & 4 & 14.3 \\
\hline Market access & 2 & 7.1 \\
\hline Improve business image & 2 & 7.1 \\
\hline Improve staff awareness & 2 & 7.1 \\
\hline Statutory requirement & 1 & 3.6 \\
\hline Business philosophy & 1 & 3.6 \\
\hline Improve quality from supplier & 1 & 3.6 \\
\hline & & \\
\hline Number of respondents & 28 & \\
\hline
\end{tabular}


Table 2: Perceived differences in the benefits of quality assurance systems between adopters and non adopters

\begin{tabular}{|l|c|c|c|c|c|}
\hline \multirow{2}{*}{ QA systems.... } & \multicolumn{2}{|c|}{ Non adopters } & \multicolumn{2}{c|}{ Adopters } & \multirow{2}{*}{ Sig } \\
\cline { 2 - 5 } & Mean & SD & Mean & SD & \\
\hline provide a competitive advantage & 4.14 & 1.68 & 4.14 & 1.69 & 1.000 \\
\hline improve company image & 4.29 & 1.80 & 4.68 & 1.16 & 0.479 \\
\hline increase profit margins & 3.14 & 2.04 & 2.57 & 1.37 & 0.503 \\
\hline reduce equipment damage and breakdowns & 2.80 & 1.64 & 2.93 & 1.61 & 0.877 \\
\hline gain new customers & 2.86 & 1.46 & 3.89 & 1.34 & 0.027 \\
\hline enhance communication with customers & 1.83 & 1.17 & 3.46 & 1.53 & 0.020 \\
\hline reduce the risk of product recalls & 4.29 & 1.60 & 4.32 & 1.68 & 0.960 \\
\hline improve the quality of management & 3.71 & 2.06 & 4.00 & 1.47 & 0.673 \\
\hline enable to firm to meet customer requirements & 3.00 & 2.00 & 5.25 & 1.04 & 0.024 \\
\hline improve relationships with suppliers & 2.50 & 1.64 & 3.68 & 1.44 & 0.026 \\
\hline improve relationships with customers & 3.14 & 1.77 & 4.04 & 1.69 & 0.224 \\
\hline improve market share & 2.60 & 0.89 & 4.43 & 1.35 & 0.007 \\
\hline provide evidence of legal compliance & 3.67 & 2.16 & 4.57 & 1.43 & 0.207 \\
\hline improve food quality and safety & 4.57 & 1.81 & 4.68 & 1.30 & 0.859 \\
\hline provide customer assurances & 3.60 & 1.82 & 5.26 & 1.09 & 0.009 \\
\hline avoid negative publicity & 2.50 & 1.52 & 3.61 & 1.77 & 0.165 \\
\hline increase employee motivation & 3.20 & 2.17 & 3.54 & 1.43 & 0.657 \\
\hline increase operational efficiency & 3.00 & 2.00 & 3.68 & 1.49 & 0.322 \\
\hline streamlines communication & 2.86 & 1.86 & 2.96 & 1.71 & 0.885 \\
\hline identifies strengths and weaknesses & 3.86 & 1.86 & 3.75 & 1.53 & 0.875 \\
\hline enhances export competitiveness & 3.50 & 1.08 & 3.12 & 1.76 & 0.698 \\
\hline access to new markets & 3.50 & 1.22 & 3.89 & 1.60 & 0.581 \\
\hline market leadership & 3.17 & 1.47 & 4.04 & 1.29 & 0.153 \\
\hline reduce legal liability & 4.00 & 1.83 & 4.32 & 1.66 & 0.655 \\
\hline
\end{tabular}

where 1 is "I disagee a lot" and 6 is "I agree a lot"

Table 3: Main barriers to adoption of QA programs by non adopters

\begin{tabular}{|l|c|c|}
\hline & $\mathrm{N}$ & $\%$ \\
\hline High cost of quality assurance & 3 & 42.9 \\
\hline Selling/closing the business & 2 & 28.6 \\
\hline Company structure & 2 & 28.6 \\
\hline Lack of time/resources & 2 & 28.6 \\
\hline No legal requirement & 2 & 28.6 \\
\hline No good training/assistance & 1 & 14.3 \\
\hline Prefer own QA system & 1 & 14.3 \\
\hline Customers have not asked for it & 1 & 14.3 \\
\hline No return on investment & 1 & 14.3 \\
\hline Limited access to information & 1 & 14.3 \\
\hline No identified benefit & 1 & 14.3 \\
\hline & & \\
\hline Number of respondents & 7 & \\
\hline
\end{tabular}


Table 4: Main constraints experienced in the adoption of QA programs

\begin{tabular}{|l|c|c|}
\hline & $\mathrm{N}$ & $\%$ \\
\hline Reluctance by employees & 10 & 37.0 \\
\hline Doubling up on paperwork & 8 & 29.6 \\
\hline High level of knowledge required & 8 & 29.6 \\
\hline Not enough qualified staff & 7 & 25.9 \\
\hline No major barriers & 6 & 22.2 \\
\hline High costs of certification/auditing & 6 & 22.2 \\
\hline Lack of time & 5 & 18.5 \\
\hline Suppliers unable to conform & 4 & 14.8 \\
\hline Need to identify critical areas of business & 4 & 14.8 \\
\hline No interest from customers & 3 & 11.1 \\
\hline Need for staff to retain records & 3 & 11.1 \\
\hline Customer requirements too high & 2 & 7.4 \\
\hline Changing customer specifications & 1 & 3.7 \\
\hline Finding a training provider & 1 & 3.7 \\
\hline Change/improve facilities/procedures & 1 & 3.7 \\
\hline & & \\
\hline Number of respondents & 27 & \\
\hline
\end{tabular}




\section{Table 5: Importance of barriers/constraints to adoption of QA systems between adopters and non adopters}

\begin{tabular}{|l|c|c|c|c|c|}
\hline & \multicolumn{2}{|c|}{ Non adopters } & \multicolumn{2}{c|}{ Adopters } & \multirow{2}{*}{ Sig } \\
\cline { 2 - 5 } & Mean & SD & Mean & SD & \\
\hline High cost of implementation & 3.83 & 2.14 & 4.37 & 1.42 & 0.450 \\
\hline Complexity and differences between systems & 4.14 & 1.35 & 4.30 & 1.44 & 0.800 \\
\hline Lack of time & 4.17 & 1.73 & 4.15 & 1.35 & 0.977 \\
\hline Lack of employee motivation & 3.83 & 1.72 & 4.07 & 1.44 & 0.723 \\
\hline Lack of financial resources & 4.14 & 1.68 & 3.70 & 1.49 & 0.502 \\
\hline Low awareness of QA benefits & 4.29 & 1.98 & 3.89 & 1.48 & 0.558 \\
\hline Organisational resistance & 2.50 & 1.64 & 3.31 & 1.40 & 0.228 \\
\hline Other priorities more important & 3.71 & 1.80 & 3.35 & 1.60 & 0.602 \\
\hline Organisational pursues short term goals & 3.71 & 1.70 & 2.38 & 1.39 & 0.040 \\
\hline Inability to choose which QA system to adopt & 2.80 & 1.64 & 2.33 & 1.44 & 0.519 \\
\hline Business too small & 4.86 & 0.90 & 2.78 & 1.50 & 0.001 \\
\hline Increased paperwork & 4.43 & 1.51 & 4.11 & 1.58 & 0.636 \\
\hline Uncertainty of value of QA in the market & 3.86 & 1.57 & 3.43 & 1.50 & 0.508 \\
\hline High cost of certification/auditing & 5.00 & 1.16 & 4.68 & 1.44 & 0.589 \\
\hline Insufficient drivers/incentives & 5.14 & 1.07 & 3.46 & 1.70 & 0.019 \\
\hline No customer requirements/need & 4.57 & 1.62 & 2.57 & 1.86 & 0.014 \\
\hline Poor internal communication & 2.17 & 1.17 & 2.58 & 1.55 & 0.550 \\
\hline Internal budgetary constraints & 3.86 & 1.77 & 2.48 & 1.34 & 0.030 \\
\hline Difficulty in obtaining external funds & 4.00 & 1.55 & 2.76 & 1.69 & 0.037 \\
\hline Current system is adequate & 3.67 & 2.25 & 3.81 & 1.94 & 0.870 \\
\hline Lack of government support & 4.86 & 1.46 & 3.81 & 1.92 & 0.190 \\
\hline Uncertainty about regulatory requirements & 4.17 & 1.83 & 3.65 & 1.81 & 0.537 \\
\hline Poor staff knowledge/skills & 3.67 & 1.63 & 3.50 & 1.75 & 0.833 \\
\hline Lack of records & 2.33 & 1.21 & 2.71 & 1.72 & 0.611 \\
\hline Current products meet customers requirements & 5.17 & 0.75 & 4.04 & 1.73 & 0.021 \\
\hline Lack of experienced consultants & 3.43 & 2.15 & 3.08 & 1.71 & 0.654 \\
\hline Poor quality information/conflicting information & 4.00 & 2.00 & 2.88 & 1.64 & 0.160 \\
\hline Lack of promotion of QA & 5.29 & 0.95 & 3.12 & 1.61 & 0.002 \\
\hline Duplication of effort & 3.14 & 1.07 & 3.56 & 1.58 & 0.519 \\
\hline Deficiencies in training & 4.29 & 1.11 & 3.00 & 1.62 & 0.011 \\
\hline QA is not a statutory requirement & 4.29 & 1.89 & 2.92 & 1.72 & 0.024 \\
\hline
\end{tabular}

where 1 is "I disagee a lot" and 6 is "I agree a lot" 